\title{
Pros

\section{"POR MÍ Y POR LOS DEMÁS": RESISTENCIA, COMUNIDADES Y COMUNISMO EN EPISODIOS DE UNA GUERRA INTERMINABLE DE ALMUDENA GRANDES}

\author{
"FOR ME AND FOR THE OTHERS": RESISTANCE, COMMUNITIES \\ AND COMMUNISM IN EPISODIOS DE UNA GUERRA INTERMINABLE BY \\ ALMUDENA GRANDES \\ Aránzazu Calderón Puerta \\ Universidad de Varsovia \\ a.calderon@uw.edu.pl
}

\begin{abstract}
"Mirad", dice el historiador, "el pasado obedece a mi interpretación" (Keith Jenkins)
\end{abstract}

ResUmen: A diferencia de lo que ha sido la nota predominante en la tradición historiográfica, la saga Episodios de una guerra interminable de Almudena Grandes se aleja del modelo de muchos historiadores, para quienes "todo se mueve en torno a la secuencia «acontecimiento, relato, primacía de lo político» cuando se pone el énfasis en la toma de decisión ejercida por individualidades poderosas" (Ricœur 2010: 317). En esta versión de la posguerra española se evita destacar el papel de tales individualidades, ya que es el colectivo -en concreto, la red de comunidades de resistentes antifranquistas- y su actividad continuada lo que posibilitaría el cambio histórico a largo plazo. La actividad de una comunidad en un entorno geográfico distinto en cada una de las novelas de la serie (Toulouse, Jaén, Madrid y Buenos Aires) está interrelacionada con la de las demás, de modo que su suma perfila la acción conjunta de un amplísimo sujeto político colectivo tradicionalmente subrepresentado en la esfera pública española. En esta ficción novelesca la resistencia comunista adquiere la forma de comunidades -políticas, pero sobre todo emocionales- que colaboran entre sí.

PALABRAS CLAVE: Resistencia antifranquista, comunidades, comunismo, posguerra española

ABSTRACT: Unlike the tradition in historical narration, the series Episodios de una guerra interminable by Almudena Grandes presents a narrative model far away 
from the dominant one, in which "everything moves around the sequence 'event, discourse, supremacy of politics' putting an enphasis on the making a decision of powerful individuals" (Ricœur 2010: 317). In this novel version of the post-war period, Grandes avoids to underline the role of such individuals, because it is a group -in particular, the network of anti-Franco members of the resistance- and their constant activity who made possible the historical change in the long term. The political activity of each community in a different geographical context in every novel -Toulouse, Jaén, Madrid and Buenos Aires- is interconnected so that the conjuction of all of them outlines the coordination of a huge collective political subject, traditionally underrepresented in the Spanish public sphere. In this historical fiction the communist resistance is articulated in political, but especially emotional communities that cooperate one with another.

Keywords: Anti-Franco Resistance, Communities, Communism, Spanish PostWar Period

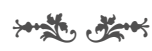

\section{INTRODUCCIÓN}

En el presente artículo pretendo indagar acerca de los límites, cada vez más borrosos, entre dos disciplinas -historia y literatura- que se caracterizan, ahora más que nunca, por una impregnación recíproca según Isabel Burdiel (2015). La investigadora destaca que desde el realismo del siglo XIX -género en el que se inspira Almudena Grandes para su ambicioso proyecto narrativo Episodios de una guerra interminable - se viene produciendo un cruce de objetivos, intereses y estrategias narrativas entre discurso histórico y novelístico.

La saga de novelas de Grandes recupera acontecimientos -como la invasión del valle de Arán por las fuerzas de la Unión Nacional Española en octubre de 1944, la lucha armada de los maquis en el monte hasta bien entrados los años cincuenta, la organización de la resistencia en la capital, etc.- transformándolos en hitos de la historia nacional, en momentos cruciales que adquieren así un valor simbólico. Tal y como afirma Hyden White, ningún acontecimiento histórico es en sí mismo trágico o cómico: depende únicamente del tipo de estructura narrativa en el que la historiadora o el historiador (y por ende, quien escribe novela de la memoria) lo sitúe como elemento destacable, y que adquiere con ello fuerza aclaratoria. Focalizando la atención del público lector en estos sucesos concretos, Grandes lleva a cabo un proceso de codificación y recodificación de la narración histórica durante el cual se corrige la percepción primaria de los acontecimientos representados (White 2003). En este sentido, Paul Ricœur destaca también el carácter activo de la operación histórica: "la representación en el plano histórico no se limita a conferir ropaje verbal a un discurso cuya coherencia sería completa antes de hacerse literatura, sino que constituye una 
operación de pleno derecho que tiene el privilegio de hacer emerger el objetivo referencial del discurso histórico" (Ricœur 2010: 313, subrayado mío). El objetivo del presente artículo será, en consecuencia, responder al interrogante: ¿qué significación aclaratoria adquieren los hitos históricos recreados en la ficción como acontecimientos trágicos y hechos determinantes para la comprensión de la historia española del siglo $\mathrm{xx}$ ?

Episodios de una guerra interminable supone un buen ejemplo de cómo la novela memoralística actual plantea una manera compleja de (re)crear el pasado. ${ }^{1}$ Al igual que en la labor del historiador, pero con otras herramientas, en este discurso "[e]l tiempo se acorta, se seleccionan y se destacan ciertos detalles, se concentra la acción, las relaciones se simplifican, no para alterar [deliberadamente] [...] los acontecimientos sino para [...] dotarles de significado" (Lowenthal 1998: 218). La novela (y en nuestro caso concreto, la memorialista) permite siguiendo de nuevo a Burdiel (2015)- la exploración del significado social de personajes singulares y anónimos, recuperando de este modo las zonas de lo subjetivo, lo íntimo, las emociones, etc. -es decir, la polifonía característica de la novela para Bajtín (1989) - y al mismo tiempo todo aquello que tradicionalmente quedaba fuera de la historia oficial. "Un proceso estrechamente asociado, y coadyuvante", nos recuerda la historiadora, "a la construcción de las esferas, artificialmente separadas, de lo público y lo privado, lo personal y lo colectivo, las pasiones y los intereses" (Burdiel 2015: 264). La interrelación de estas esferas, tejido argumental de los textos literarios objeto de mi estudio, demuestra hasta qué punto "la Historia (con mayúsculas) ocurre dentro del relato de ficción y, como tal, inevitablemente, ocurre como conflicto" (Burdiel 2015: 278, subrayado mío). A mí me interesará plantearme la cuestión de cuáles pueden ser los posibles sentidos de la representación del pasado en el género de la novela de la memoria realista cuando la autora busca construir una versión alternativa a la de la narración historiográfica al uso. ${ }^{2}$

\section{LA VOZ (AUTORIAL) DE LA HISTORIA}

Como señala en su libro Keith Jenkins (2009), la historiadora o el historiador no tiene acceso directo al objeto de su estudio -el pasado-, pues este es sencillamente inalcanzable desde el presente e inabarcable en todos sus aspectos. Puede tan solo trabajar con materiales sobre el periodo en concreto que le interesa estudiar (libros escritos por otros, documentos, archivos, fotografías, testimonios, etc.) y es a partir de ellos que configura su propia narración/versión/interpretación del pasado. De la misma manera, Almudena Grandes inventa una trama ficcional que inserta en un detalladísimo contexto histórico: recrea personajes, acontecimientos y lugares reales de la posguerra, realizando para

\footnotetext{
${ }^{1}$ A partir de la novela El corazón helado, la obra literaria y como articulista de Almudena Grandes se enmarca en lo que Sebastiaan Faber denomina "acto afiliativo" (2014).

2 Según la propia Grandes, el punto de vista de la cultura oficial sobre la guerra y la posguerra en gran parte se sigue nutriendo de la historiografía franquista (Calderón Puerta y MoszczynskaDürst 2016).
} 
ello un inmenso trabajo de documentación previo a la escritura. ${ }^{3}$ En el epílogo de cada uno de los Episodios de una guerra interminable la escritora madrileña aporta una descripción detallada de dicho trabajo, desvelando sus fuentes orales y bibliográficas, así como los orígenes de su inspiración. Ello se completa con la fotografía que ilustra cada una de las portadas (única imagen de las obras), que ambientan al lector o lectora en los años en los que predominantemente se desarrolla la acción, las décadas de los cuarenta y cincuenta. ${ }^{4}$

En todas las novelas de la serie publicadas hasta el momento (excepto en El lector de Julio Verne) la perspectiva de los y las protagonistas en primera persona alterna con capítulos de una voz narrativa omnisciente que es posible identificar bien con la perspectiva personal de la propia escritora, bien con los que podríamos denominar la voz de la Historia. Mi percepción es que, como recurso estilístico - pese a las intenciones declaradas de la autora-funciona más bien como lo segundo, ya que predomina la tercera persona tendencialmente distanciada e impersonal. ${ }^{5}$ Esta voz aclara procesos del marco histórico, amplía la información para el público lector aportando datos muy concretos (fechas, lugares, personas, acontecimientos o documentos) y sitúa los hechos presentados en las partes ficcionales en un contexto más amplio. Veamos un ejemplo extraído de Los pacientes del doctor García:

\section{ES 4 DE DICIEMBRE DE 1947 Y EL PRESIDENTE PERÓN RECIBE EN LA CASA ROSADA.}

Sus visitantes son seis y forman un grupo que, a primera vista, podría parecer heterogéneo. Sólo uno de ellos es argentino, aunque goza además de otra nacionalidad, diferentes de las de sus compañeros, que a su vez son diferentes entre sí. Sin embargo, todos han entrado en el país en 1947 con pasaporte español legal. [...] Se trata de Pierre Daye, René Lagrou, Georges Gilbaud, Radu Ghenea y Horst Alberto Carlos Fuldner, criminales de guerra huídos de la justicia internacional que han logrado exiliarse a la Argentina gracias a la ayuda del gobierno franquista. Perón está interesado en acoger a técnicos y científicos,

\footnotetext{
${ }^{3}$ Recordemos que el género literario en el que se inspira es la novela realista del siglo XIX, y en concreto la serie de los Episodios nacionales de Benito Pérez Galdós.

${ }^{4}$ En este sentido, el papel de los paratextos resulta fundamental para comprender hasta qué punto existe un paralelismo entre la labor del profesional de la historia y de la escritora de novela memorialista que busca una representación panorámica realista de toda una época.

${ }^{5}$ Aunque en las notas de la autora Grandes se la atribuye a sí misma, durante la lectura de las obras quien lee no tiene por qué percibirlo de este modo. Por ejemplo, la primera novela, Inés y la alegría, tiene tres ejes, como se señala en el último apartado: 1) el nivel del poder, las alturas desde las cuales se decidió la suerte de los guerrilleros; 2) "El tercer narrador es un personaje real, porque soy yo. Los cuatro paréntesis intercalados entre los capítulos de ficción del libro recogen mi versión personal de aquel episodio, lo que yo he podido averiguar, documentar, relacionar e interpretar, para elaborar lo que sólo pretende ser una hipótesis verosímil de lo que sucedió en realidad. Si me he atrevido a proponer mi propia versión es porque [...] nunca ha llegado a existir una versión oficial de lo que ocurrió" (Grandes 2011: 723); y 3) dos narradores en primera persona, Inés y Galán, dos militantes comunistas de base. Como indica la autora, "[a] pesar de esa distancia [entre los dos niveles] las páginas de la novela están perforadas por túneles y atajos que permiten que los habitantes de las alturas del poder desciendan, de vez en cuando, hasta el nivel del suelo" (Grandes 2011: 723).
} 
civiles o militares, vinculados al Tercer Reich, con el objeto de convertir a Argentina en una potencia. (Grandes 2017: 451-453)

Como podemos observar, esta voz que rescata determinados acontecimientos del pasado suele mantener un tono distanciado, bastante en la línea de lo exigido al profesional de la historia en su tarea. Sin embargo, la narradora omnisciente en ocasiones se inmiscuye en su propia narración de los hechos con un tono más emocional, recurriendo con frecuencia a la ironía, pero sin desvelar su identidad hasta las últimas páginas. Un ejemplo del uso de la ironía lo encontramos en uno de los numerosos fragmentos dedicados en Inés y la alegría a la figura de Francisco Franco:

Es lo que tienen los dictadores, que primero ponen mucho cuidado en eliminar de su entorno a cualquier persona con talento suficiente para hacerles sombra, y después echan de menos su brillantez. Y sin embargo, aunque él no puede saberlo [...] [el 19 de octubre de 1944 en el Palacio de El Pardo, A. C. P.] da una imagen lamentable de sí mismo, tan bajito, tan gritón y tan cabreado, en su propio despacho... (Grandes 2011: 235, subrayado mío)

Este recurso estilístico dota de una evidente carga moral a los acontecimientos representados, de modo que en ciertos momentos la narración está lejos de ser neutra. Sin embargo, como he señalado, en líneas generales en los Episodios predomina la intencionalidad objetiva de lo que denomino aquí la voz narrativa de la Historia. Para construirla -como hemos visto-Almudena Grandes recurre a las mismas fuentes y medios de los y las profesionales de la historiografía, aunque lo hace con los objetivos bien distintos que marcan las diferentes aportaciones complementarias entre sí- del discurso literario y del discurso histórico a la hora de recuperar y comprender el pasado. ${ }^{6}$

En la serie Episodios de una guerra interminable, cuando aparece, la voz de la Historia plantea hipótesis acerca de las emociones que experimentaron o pudieron experimentar personas reales clave -según la narración histórica dominante- del periodo de la posguerra, y sobre cómo tales emociones influyeron o pudieron influir en el desarrollo de los acontecimientos. Por ejemplo, tal y como explica Katarzyna Moszczyńska-Dürst (2017), en Inés y la alegría el amor romántico es presentado como motor tanto de la trama de la novela como de la historia. Así, según la hipótesis que se defiende en la novela, Dolores Ibárruri, por estar enamorada de Francisco Antón, se preocupó más por el destino del mismo que por el del PCE en Francia, lo cual la llevó a tomar la decisión errónea de dejar este último en manos de Carmen de Pedro. Esta, por su parte, se enamora del ambicioso y carismático Jesús Monzón, quien la mantuvo supuestamente como su pareja hasta conseguir su objetivo político: hacerse con la dirección del Par-

\footnotetext{
6 Para Jenkins, aplicar la radical dicotomía entre arte y ciencia respectivamente a literatura e historia es obsoleta (2009: 71), producto de la ideología. En su opinión, la historia se escribe "para alguien", es intersubjetiva e interpretativa. Está siempre ideológicamente posicionada, como todo discurso en la cultura y, en este sentido, estima que hablar de objetividad y equidistancia en el caso de la disciplina histórica son meras quimeras.
} 
tido en España y Francia, y organizar una invasión militar desde los Pirineos. Tal operación no resultó un éxito por muy poco, y a punto estuvo de que el curso de la historia de España fuera bien distinto:

Por un pelo, Franco sigue viviendo en el Pardo durante treinta y un años más. Por un pelo, la cara de Jesús Monzón no se repite en millones de sellos de correos y de billetes de banco. [...] Por un pelo, aquel hombre a quien ya nadie recuerda, no se convierte en el héroe, en el salvador, en el padre de la Patria. (Grandes 2011: 46)

Este es justo el otro aspecto que los capítulos narrados desde la voz de la Historia están interesados en destacar. Esta perspectiva en apariencia omnisciente resulta no serlo del todo en la medida en la que presenta a menudo hipótesis sobre el pasado. Pese a exponer datos y hechos bien documentados, se plantea continuamente las preguntas de cómo pudo ser, cómo podría haber sido y qué estuvo a punto de ocurrir, pero no ocurrió. En este sentido, desestabiliza la visión de una narración cerrada y fija sobre el pasado, por mucho que esté basada en documentos, presentando la posguerra como un periodo complejo, de cambios cruciales originados por meras casualidades, decisiones en muchos casos arbitrarias, azares varios y cruces casuales de personas. ${ }^{7}$ Esta visión fluctuante del pasado se logra recrear mediante el uso estilístico de verbos, adverbios, locuciones adverbiales y adjetivos que indican duda, incerteza o desconocimiento, como podemos observar en el siguiente fragmento:

Así fue o, al menos, así pudo ser. Lo único que puede afirmarse con certeza es que Carmen de Pedro y Jesús Monzón, que hasta ese momento han sido simples conocidos, de vista y poco más, se encuentran en Francia, probablemente en Toulouse y en apariencia por azar, en un día cualquiera del verano, agosto, quizás julio, incluso septiembre, de 1939. Los detalles se desconocen, porque seguramente él se encargó de que nadie fuera testigo de un encuentro que cambió muchas cosas, y estuvo a punto de cambiarlas todas. (Grandes 2011: 21, subrayado mío)

Si los historiadores "se ven obligados a aportar su propia dosis de imaginación, con objeto de llenar los espacios en blanco [...] para que sus relatos resulten lo más exhaustivos posible" (Jenkins 2009: 60), la voz narrante de de Grandes pone en evidencia en su propio discurso histórico-literario cómo rellena esos mismos huecos, ofreciendo distintas opciones para hacerlo. Con su peculiar manera de reconstruir y cuestionar al mismo tiempo la imagen de la posguerra, la escritora madrileña problematiza la ambición de homogeneidad y continuidad lógica a la que aspira en principio todo texto historiográfico, al plantear que los propios documentos que sirven de base de trabajo a quien reconstruye el pasado no aportan nunca suficiente información como para poder afirmar con total certeza

\footnotetext{
7 Como ocurre con algunos de los personajes de la serie, que aparecen y reaparecen en la trama de las cuatro novelas, y que el lector o la lectora puede identificar como un claro juego intertextual.
} 
cómo un acontecimiento sucedió en realidad. De acuerdo con este principio, a la hora de revisar el pasado siempre nos moveremos barajando meras suposiciones. En consecuencia, toda reconstrucción de lo acontecido se presenta como un fenómeno mucho más voluble de lo que la tradición causa-efecto de la disciplina histórica ha pretendido. La voz de la Historia de los Episodios parece cuestionar con su hacer precisamente lo que se ha venido considerando en la tradición cultural occidental... la voz de la Historia.

\section{OTROS MOTORES DE LA HISTORIA: COMUNISMO Y COMUNIDAD}

A diferencia de lo que ha sido la nota predominante en dicha tradición historiográfica, la propuesta novelesca de Grandes se aleja del modelo de muchos historiadores e historiadoras, para quienes "todo se mueve en torno a la secuencia 'acontecimiento, relato, primacía de lo político' cuando se pone el énfasis en la toma de decisión ejercida por individualidades poderosas" (Ricœur 2010: 317). En esta versión alternativa de la posguerra española se evita destacar el papel de individualidades poderosas y sus decisiones políticas, ya que es el colectivo -en concreto la red de comunidades de resistentes antifranquistas- y su actividad continuada lo que posibilitaría el cambio histórico a largo plazo. La actuación de cada comunidad en un entorno geográfico distinto (el exilio en Toulouse en Inés y la alegría, los maquis de la sierra de Jaén en El lector de Julio Verne, la organización en la calle y en las cárceles de Madrid en Las tres bodas de Manolita, el espionaje organizado en Madrid y Buenos Aires en el caso de Los pacientes del doctor García) está interrelacionada con la de las demás, de modo que su suma perfila la acción conjunta de un sujeto colectivo subrepresentado tradicionalmente en la esfera pública española. En la ficción novelesca la resistencia comunista adquiere, por tanto, la forma de comunidades (políticas pero sobre todo emocionales ${ }^{8}$ ) que colaboran entre sí.

En cada una de las novelas de la serie el personaje en el que se focaliza la narración pasa por un rito de iniciación -que termina a menudo con una suerte de iluminación- resultado de su integración en una comunidad dada de resistentes. En dicho colectivo resultan siempre fundamentales el principio de solidaridad (que cohesiona la red de activistas) y la (re)producción del sentimiento de pertenencia. Por ejemplo, Inés habla en los siguientes términos del grupo de militares antifascistas, instalados en el valle de Arán, al que termina uniéndose:

unos días que nos enseñaron a ser felices [...] aquel dorado paréntesis que [...] nos vinculó siempre, para siempre, a todos los habitantes de aquella casa que nunca desaparecerá, que seguirá existiendo mientras quede uno solo de nosotros para recordarla. (Grandes 2011: 312)

Por su parte Guillermo, en Los pacientes del doctor García, toma la decisión de trabajar como médico clandestino del PCE durante la posguerra. Describe así ese día:

${ }^{8}$ En este sentido, las emociones son el cinturón transmisor y sostenedor del compromiso político. 
El hombre que salió de aquel café [...] parecía el mismo que había entrado media hora antes, pero no lo era, jamás volvería a serlo. En mi interior se había operado una transformación fundamental [...] la conciencia de que acaba de integrarme en una organización clandestina no sólo no menoscabó mi alegría, sino que la agigantó. En el sitio donde yo sentía que tenía que estar, trabajé tanto y tan bien como pude por mí y por los demás... (Grandes 2017: 274, subrayado mío)

En este sentido, resulta llamativo que en las tramas novelescas tenga mayor preponderancia narrativa y emocional la comunidad como principio ideológico vertebrador que el propio comunismo, pese a articular este último el marco político de la actividad que realizan la inmensa mayoría de los personajes protagonistas. En efecto, el discurso estrictamente político se encuentra más bien ausente en estos textos literarios. ${ }^{9}$ Sin embargo, los valores de "lo común" (raíz etimológica del término "comunismo") sí constituyen el marco ideológico ${ }^{10}$ que permite la transformación tanto personal (de Inés, Galán, Nino, Manolita, Guillermo, Manolo, María y Germán, protagonistas de las cinco novelas publicadas hasta el momento) como social (del conjunto la sociedad española) en el mundo ficcional de Grandes. Acerca del papel político de la solidaridad en la sociedad civil, Pepe el Portugués le cuenta a Nino, un chaval de apenas nueve años:

Es que la gente, ahora, no entiende estas cosas [...]. Antes sí, antes, cuando la República, lo entendía todo el mundo, porque había huelgas, cajas de resistencia y sindicatos que prestaban dinero sin interés, que socorrían a las viudas y construían colegios para los huérfanos, pero ahora... Es como si aquello no hubiera pasado, como si nadie se acordara de nada. (Grandes 2012: 176, subrayado mío) ${ }^{11}$

Este predominio de la presencia de lo común y la comunidad en detrimento del propio discurso comunista -relativamente secundario en las historias de vida de los personajes- se articula, entre otros, en el paso simbólico de la comunidad de elección a la familia de elección. Esta última, sin embargo, terminará fusionándose con la biológica en todas las obras de la serie publicadas hasta el momento. Veamos un ejemplo. En Inés y la alegría, la protagonista decide abandonar-física e ideológicamente- a su familia burguesa, representante de la España conservadora y franquista convencida. ${ }^{12}$ La joven renuncia al vínculo biológico y afectivo original para pasar a incorporarse a su familia de elección: los comunistas. Ambos grupos se pueden identificar con las denominadas "dos Españas" y con

\footnotetext{
9 Son más bien anecdóticos los momentos en los que aparecen referencias a los conceptos de lucha de clases, revolución del proletariado, abolición de la propiedad privada, etc. Sin embargo, la mera representación del PCE supone una novedad en el conjunto de la denominada novela de la memoria, como señaló en su momento Isaac Rosa en la novela El vano ayer (2004: 58).

10 En mi trabajo concibo la ideología como la manera ético-política de entender el mundo, sin connotaciones negativas.

${ }^{11}$ Como podemos observar, es además un valor que se vincula al periodo histórico de la Segunda República.

12 Sobre todo la figura del hermano mayor, Ricardo, marcadamente patriarcal.
} 
dos movimientos políticos de signo contrario (fascismo y comunismo respectivamente) en los que se embarcaron millones de individuos el siglo pasado.

El proceso que experimenta la protagonista es el de una toma de conciencia que termina por unirla a un colectivo político y emocional. La figura de Inés reúne los rasgos de autonomía, agencia, libertad de acción y elección que desde el siglo XIX y por influencia romántica entendemos como característicos de la identidad individual. Pero de su extensa historia vital resulta que tales valores solo pueden realizarse de manera completa en correlación con otros, en el marco de un grupo de acogida. En este sentido, los valores de los dos protagonistas de esta primera novela (Galán e Inés) coinciden con los del grupo de exiliados al que terminan integrándose: se "funden" con ellos para terminar configurando una comunidad. Así, a partir de la segunda parte de la novela, el "yo" de ambas voces narrativas (femenina y masculina) se diluye cada vez con mayor frecuencia en un "nosotros" colectivo. Uno de los innumerables ejemplos de este fenómeno son las palabras de Inés al poco de instalarse en Toulouse:

En febrero de 1945, aquel mes maldito, empecé a vivir en la taberna más que en mi casa, y mis socias, mis clientes, me ayudaron a soportar la ausencia de Galán como una familia adoptiva, flamante y benéfica. Aquella solidaridad, que fluía en todas las direcciones como un río de incontables brazos... (Grandes 2011: 359, subrayado mío)

Como podemos observar, el sentido de pertenencia en el caso de Inés está basado en vínculos tanto emocionales como políticos. Un ejemplo más de ello es el siguiente fragmento de la narración de Galán:

Daba igual que el Ninot [un camarada homosexual, A. C. P.] hubiera muerto de un infarto, que no lo hubieran derribado los disparos de un pelotón. Se había activado el protocolo de los fusilamientos, porque había muerto uno de los nuestros. Eso había sido el Ninot, para lo bueno y para lo malo, para lo mejor y para siempre, uno de los nuestros. (Grandes 2011: 421-422, subrayado mío)

En la trama de la novela queda claro que el Partido como familia política es relevante para el grupo, pero a fin de cuentas secundario: ya desde la aventura de la incursión al valle de Arán en octubre de 1944 los protagonistas de la obra, militantes de base, critican de manera sistemática a los dirigentes de la cúpula. Este votum separatum representa la voz de las bases, que tradicionalmente pasan desapercibidas y terminan siendo omitidas por completo en la narración histórica oficial. El PCE, como explica Inés, es "nuestra única casa, nuestra patria, nuestra familia". Y aunque afirma que "había sido mi libertad, y no otra cosa, lo que me había hecho comunista" (Grandes 2011: 535), tiene muy claro que en su cocina manda ella, y no el Partido ${ }^{13}$.

\footnotetext{
${ }^{13}$ El espacio de la cocina se convierte así, paradójicamente, en el espacio de agencia propia tanto para Inés como para la comunidad femenina de socias a la que pertenece.
} 
Esta singular familia adoptiva en el exilio se agrupa en torno a la figura de un padre simbólico, el inteligente y seductor Jesús Monzón, al que les une (una vez más) un vínculo tan emocional como político. Lola, una camarada, se lo explica a Inés de la siguiente manera: "Carmen [de Pedro] se enamoró de él, sí, y yo también, y Manolo, y Gimeno, y Domingo, y Ramiro, y Comprendes, y el Sacristán, y tu marido. Tu marido más que ninguno [...]. Todos nos enamoramos de Jesús" (Grandes 2011: 537-538). Tal paternidad simbólica se compensa narrativamente con la mítica figura maternal de Dolores Ibárruri, quien posee asimismo el don de atraer y encantar, aunque sin la vertiente erótica que distingue al carismático Monzón: "Madre con mayúscula y por antonomasia, madre universal también con la minúscula de los mimos, y las caricias que reparte hoy, y repartirá muchos otros días, entre sus nietos simbólicos, los hijos de sus hijos, Madre Dolores" (Grandes 2011: 458).

Con posterioridad, los límites entre la familia de elección y la de sangre se volverán borrosos. Así, de los tres niños que se lleva el grupo de militares a Francia tras la aventura en Arán, dos (Matías y Andrés) terminarán siendo adoptados por uno de ellos. El segundo se convierte con el paso del tiempo en miembro de la familia de Inés y Galán al casarse con una de sus hijas: “¿Cómo te vas a casar? [...] ¡Pero si [Andrés] es de la familia! ¿Es que no lo entiendes?", le espeta el padre. A lo que ella responde: "- ¿De la familia? No, papá, yo me apellido González Ruiz, y él, Rios Malpica" (Grandes 2011: 611). En efecto, ambas familias confluyen a la postre. $^{14}$

Por añadidura, la familia de sangre que surge del matrimonio de los protagonistas de Inés y la alegría reproduce simbólicamente a la adoptiva. Sus hijos y nietos reciben los nombres de las personas que han marcado la trayectoria vital de ambos, es decir, los familiares de elección: Miguel (en recuerdo de El Bocas, caído en combate en 1944), Virtudes (en recuerdo de la amiga y excriada de Inés en Madrid durante la guerra), Adela (por su cuñada) y Fernando (nombre del padre, o sea, el propio Galán). Además, una de las nietas recibirá el nombre de su abuela Inés. La familia, como vemos, es entendida en un sentido amplio: no solo como una agrupación de personas ligadas por la sangre o el marco legal, sino como un vínculo profundo y duradero.

En la segunda novela de la serie, El lector de Julio Verne, el protagonista, Nino, tiene que enfrentarse al dilema moral de elegir entre su familia de origen y la de elección (la comunidad que conforman su amigo Pepe el Portugués y las habitantes del cortijo de las Rubias). En su caso podemos hablar de una oposición entre el padre real-Antonio, guardia civil víctima y a la vez reproductor del sistema de represión franquista: "era un asesino y un pobre hombre, un asesino y un hombre bueno, un asesino y un desgraciado, un asesino y su propia víctima" (Grandes 2012: 223)- y el padre simbólico, que representa Pepe Moya, uno de los

\footnotetext{
${ }^{14}$ La comunidad de elección es tratada como familia. Así, en el restaurante que regenta Inés con sus socias está siempre disponible la "mesa de la familia": "tres o cuatro [mesas] juntas, en realidad, que todos los días montábamos y reservábamos sin saber cuántos de los hombres de Bosots [los militares que participaron en la invasión de Arán, A. C. P.] iban a venir a ocuparla" (Grandes 2011: 519).
} 
resistentes. Gracias a su amistad con este último, el crío recibirá una educación sentimental y política que lo alejarán del ambiguo modelo que había constituido su padre hasta ese momento:

\begin{abstract}
Pepe el Portugués se marchaba, me dejaba solo, huérfano con padre y madre [...]. Se marchaba, y era la persona más importante de mi vida, un amor más fuerte que el amor, pero se marchaba, y sin embargo se quedaba en mí, porque yo sería otro niño, otro Nino, si no le hubiera conocido a los nueve años. [...] Él me había convertido en alguien distinto, en alguien mejor, me había enseñado qué clase de hombre quería llegar a ser, a quién me gustaría parecerme. (Grandes 2011: 386, subrayado mío)
\end{abstract}

Fascinado por la misteriosa figura del Portugués, influenciado por las palabras de la maestra represaliada Doña Elena, enamorado en secreto de la nieta de esta, Nino -observador de las acciones y actitudes de las indomables Rubiasno tardará en quedar integrado en esta pequeña comunidad de resistentes de su pueblo natal. Así, Doña Elena le anuncia cierto día: "Ahora, vosotros sois mi familia" (Grandes 2012: 247). Nino reacciona pensando que "en aquel pronombre personal cabían tantas cosas" (Grandes 2012: 247).

\title{
3. MÁs alLÁ de LAS VÍ́ctimAS: RESISTENCIA Y EMANCIPACIÓN
}

La serie Episodios de una guerra interminable supone una singular recreación de los años cuarenta y cincuenta. Centrada en un grupo tradicionalmente excluido de la narración historiográfica hegemónica en España, actualiza nuestra percepción de estas oscuras décadas resituando actores y acontecimientos en un mapa nuevo cuyo centro lo ocupa el antifascismo/antifranquismo, factor determinante en este proceso de explicación-aclaración histórica. Se cuestiona con ello el "régimen de verdad"15 -en términos de Foucault- que ha imperado en la esfera pública española y en el ámbito académico durante décadas, el cual otorgaba protagonismo a otros agentes del pasado. Una versión que ha venido conformando el habitus histórico-identitario dominante hasta hace bien poco en España ${ }^{16}$. En este sentido,

el "Antifranquismo" no ha constituido en nuestro país el referente legitimador de la democracia actual. Por lo menos, no de la forma en la que el "Antifas-

\footnotetext{
15 "Debemos entender la 'verdad' como un sistema de procedimientos ordenados que sirven para la producción, regulación, distribución, circulación y funcionamiento de enunciados/afirmaciones. La «verdad» está imbricada [...] con los sistemas de poder que la generan y que la confirman" (Foucault 1981: 133, citado en Jenkins 2009: 41).

${ }^{16}$ Concepto teórico que estoy desarrollando en base a la obra de Pierre Bourdieu, y que entiendo como "una ley tácita de percepción y actualización del pasado que constituye la base del consenso sobre el sentido del mundo social actual y, en consecuencia, la base del sentido común de proceso histórico. En definitiva, cada una de las interpretaciones del pasado de la que se deriva determinado modelo identitario, el cual funciona en la sociedad como instancia reguladora de la relación del individuo consigo mismo, con el grupo y con el mundo" (Calderón Puerta y Chmielewska 2019).
} 
cismo" lo fue para la democracia italiana, alemana o francesa después de la Segunda Guerra Mundial y durante décadas, aunque hoy se dé una situación distinta en cada uno de esos países. En el caso español ese elemento legitimador se identificaría con el proceso de "transición política" a la democracia liberal parlamentaria. (Tébar 2012: 15)

Recuperar el antifascismo y la Segunda República como referentes legitimadores de la democracia actual es uno de los objetivos didácticos que se proponen los Episodios de una guerra interminable, algo que la propia Grandes declara con frecuencia ${ }^{17}$. Ante un largo silencio -institucional, político, cultural y social- respecto a una tradición antifascista que existió en España y se borró de las referencias comunes compartidas, la serie de novelas, gracias a su enorme popularidad, busca abrir un hueco para que dicha la tradición entre a fomar parte de los relatos que pugnan por la hegemonía en la historia pública ${ }^{18}$.

De hecho, el dilema al que se enfrenta Nino respecto a su padre, y que es el nudo de la trama en El lector de Julio Verne, puede ser interpretado como una metáfora de la historia del país: el niño deberá integrar la verdad sobre su progenitor (es decir, la violencia que ejerce y a la que es a su vez sometido) para poder seguir adelante. En palabras de Doña Elena: "la verdad es toda la verdad, y no solo una parte. La verdad es lo que nos gusta que haya sucedido y, además, lo que ha sucedido aunque nos guste tan poco que daríamos cualquier cosa por haberlo podido evitar. Para aceptar eso también hay que ser valiente" (Grandes 2012: 198). Del mismo modo, la sociedad española debería enfrentarse a un pasado reciente cargado de violencias silenciadas y no asumidas, lo cual pasaría por el reconocimiento oficial tanto de las violencias ejercidas por actores concretos del sistema franquista como del sufrimiento de las víctimas de la represión y su reparación. No hacerlo implica culturalmente el mantenimiento del sistema simbólico generador de tales violencias. En este sentido, la transición fue un proceso demasiado apresurado, como suele asegurar Grandes en sus declaraciones.

No por casualidad las novelas de la serie terminan en la década de los setenta, con la transición española mostrada como un momento de decepción política definitiva para los miembros de la comunidad de resistentes. La postergación utópica de la recuperación de la República -la revolución ya desaparecida del horizonte de lo posible- enturbia el aparente final feliz de las novelas, un final en el que a la exaltación de la familia tradicional se le suma la de la familia de elección política ${ }^{19}$. Según el historiador Enzo Traverso, en el caso de España "el fracaso del golpe de Tejero puso fin a una turbulenta Transición hacia la democracia barriendo, junto con el franquismo, la esperanza socialista de

\footnotetext{
17 Múltiples entrevistas con la escritora así lo recogen, así como varios de sus artículos reunidos en el volumen La herida perpetua. El problema de España y la regeneración del presente (2019).

18 Se ha creado en España una Asociación de historia pública, que tiene, entre otros, "el objetivo de contribuir al debate sobre los usos colectivos del pasado y a la democratización de la razón y el conocimiento históricos", como se declara en su manifiesto.

${ }^{19}$ En efecto, todos los protagonistas de los Episodios sin excepción terminan formando una familia heteronormativa en el marco de la institución matrimonial, con numerosos hijos y nietos.
} 
aquellos que lo habían combatido" (2012: 14). La implantación de la monarquía parlamentaria terminó con la esperanza de cambio que habían traído consigo a lo largo del siglo XX las palabras "comunismo" y "revolución", las cuales -como señala Traverso- en lugar de designar una aspiración o una acción emancipadora, pasaron a evocar a partir de 1989 un universo casi exclusivamente totalitario.

Los Episodios encarnan, en fin, un intento de recuperación simbólica de determinados valores que estuvieron en el centro del discurso de las izquierdas del siglo pasado: solidaridad (de clase y no solo), lucha política por el cambio, acción directa, etc. ¿Cómo? Desde una narración sobre el pasado en la que el amor es la emoción reguladora y articuladora de trayectorias vitales marcadas por la promesa de felicidad, como en el caso de los y las protagonistas de la serie. Para ello, el grupo y sus valores constituyen el marco necesario para el cambio personal que experimenta el personaje en el centro de la narración. Se invierte así el mecanismo frecuente en las últimas décadas en historiografía, en la que -de nuevo según Traverso- con el recurso de las víctimas (de la Guerra Civil española, del Holocausto, etc.) se ha borrado la memoria de la constitución de determinados grupos sociales en sujetos políticos (2012). En cambio, en su ficción Almudena Grandes no se limita a describir el sufrimiento y las terribles consecuencias de una represión feroz, sino que convierte -y en ello resulta especialmente innovadora- a las víctimas en protagonistas de su propio proceso emancipador. Todas tomarán las riendas de su propio destino y, paradójicamente, serán mucho más felices a partir de su implicación en la resistencia antifranquista.

\section{CONCLUSIONES}

En síntesis, ¿qué tipo de representación (y por tanto interpretación) del pasado encontramos en Episodios de una guerra interminable? Personalmente, yo destacaría algunos aspectos del faraónico proyecto de Grandes que valoro sin duda como positivos por el carácter novedoso de la imagen de la posguerra que logran conformar. En primer lugar, se narra el pasado haciendo patente la acción de agentes que hasta hace bien poco no solían protagonizar el discurso historiográfico. La lucha comunitaria en estas obras visibiliza a determinados grupos sociales, considerados tradicionalmente carentes de poder (mujeres, niños, homosexuales...) y se muestra su capacidad de agencia para generar cambio social.

En segundo lugar, se evidencian los procesos de formación de comunidades políticas por medio de las emociones, así como la influencia de las mismas en la configuración de una conciencia política tanto a nivel individual como colectivo. Por añadidura, se muestra la imbricación de ambas esferas (política y emocional) en ambos niveles.

Por otra parte, las tramas novelescas permiten la reactivación para la memoria funcional (Aleida Assmann 1999) de acontecimientos políticos, sociales y culturales del pasado -hasta entonces desconocidos en gran medida para el conjunto de la sociedad- tanto de franquistas y allegados al régimen (como el aprovechamiento de la mano de obra barata de los represaliados en campos de 
trabajo, el trato institucional a sus hijas e hijos y la explotación económica de los mismos, las experiencias específicas de violencia sexual que experimentaron las "rojas" por el hecho de serlo, las torturas y asesinatos de la Brigada Político Social, etc.), como de los resistentes (la invasión del Valle de Arán en octubre de 1944 por las fuerzas de la UNE, la actividad militar de las guerrillas en el monte, la red de solidaridad y apoyo en torno a las cárceles, la actividad de los exiliados en Francia, la participación femenina en la resistencia antifranquista, etc.).

Por último, al mismo tiempo que visibiliza los mecanismos generadores de exclusión (social, cultural, económica, de género, etc.) de los parias "rojos" durante la posguerra, este proyecto narrativo revisa desde una perspectiva novedosa los conflictos y violencias de la segunda mitad del siglo xx. Los acontecimientos históricos en él recogidos se enmarcan en un contexto político e histórico más amplio, al mostrar los vínculos entre franquismo, nazismo (en relación al desarrollo de la Segunda Guerra Mundial y sus posteriores consecuencias) y las dictaduras del Cono Sur ${ }^{20}$. Aporta una visión documentada más completa del pasado al dar a conocer muchos de los complots políticos y diplomáticos que determinaron una continuidad transnacional de las violencias ejercidas por gobiernos de derechas a lo largo del siglo $x x .^{21}$

Esta panorámica recreación de (sobre todo) los años cuarenta y cincuenta en España presenta, no obstante, aspectos que deben ser objeto de crítica, entre los cuales destacaría los siguientes. En primer lugar, la bipolaridad en la representación del pasado violento, con una clara oposición entre fascistas/franquistas/nazis (retratados casi siempre en la ficción como figuras oscuras) y republicanos/antifascistas/comunistas (de comportamiento prácticamente sin tacha ${ }^{22}$ ), la cual reproduce la lógica bélica de las "dos Españas" ${ }^{\prime 23}$. En este sentido, la narración lleva implícita una fuerte carga de valoración moral del comportamiento de los personajes según su pertenencia a una u otra opción política. Mediante las emociones articuladas en la ficción literaria, esta conmueve al lector, alineándolo con los personajes positivos en el centro de la narración y su bando ${ }^{24}$.

\footnotetext{
${ }^{20}$ Sobre todo en las novelas Los pacientes del doctor García y La madre de Frankestein.

${ }^{21}$ Como afirman Aleida Assman y Sebastian Conrad, resulta imposible comprender hoy el proceso de desarrollo de los discursos de la memoria fuera de un marco de referencia global (Assman y Conrad 2010).

22 A excepción de Guillermo García, que se ve obligado a cometer un asesinato a sangre fría.

${ }^{23}$ Por supuesto, en unas novelas tan extensas y de indagación psicológica en los personajes tanto principales como secundarios las cosas no son tan sencillas, pero en líneas generales predomina esta imagen bipolar.
}

${ }^{24}$ Al respecto, señalan Izquierdo Martín y Sánchez León: "El poder de la divisoria que separa en dos comunidades de memoria [a los españoles, A. C. P.] no reside en el número de adeptos que tiene cada una de ellas en un momento concreto, sino en la intensidad con que puede llegar a ser vivida; es decir, en la fuerte valoración moral que puede conllevar el identificarse con una de esas comunidades. Esto es fuente de preocupación para algunos ciudadanos y formadores de la opinión pública; señalan éstos con acierto que las comunidades de memoria surgidas a raíz de una guerra se conforman por negación de la otra, y eso es algo que puede afectar a la convivencia cuando ambas coexisten en el mismo territorio. Sin embargo, hay que reconocer que se trata de una actividad que acompaña el ejercicio de un derecho garantizado en toda democracia pluralista: la libre identificación personal con unas ideas implica la libertad de dotarse de una 
Por otra parte, los finales familiares coincidentes de las obras invitan a una interpretación simbólica en la que la comunidad nacional aparece articulada en base al modelo - violento, a su manera- del mito del amor romántico, y en concreto de la familia convencional. De hecho, la transmisión política en la ficción va de una generación (biológica) a otra, en el marco - da la impresión casi de fatum-de la familia heteronormativa reproductora, ${ }^{25}$ en aparencia único horizonte posible para la felicidad personal, tal y como se articula esta apariencia en estas obras. Dicha transmisión, por añadidura, se lleva a cabo en exclusiva a través de la actividad de los varones -actores políticos- frente a las mujeres, que pese a sus convicciones ideológicas e incluso implicación activa en su juventud, terminan encerradas en el hogar y la esfera privada. A pesar de su intención evidentemente emancipadora, las fábulas de los Episodios refuerzan a fin de cuentas la idea de que "la heteronormatividad reproductora subyace en los mitos sobre los que se sustenta y en las leyes que construyen lo nacional" (Sabadell-Nieto 2011: 19). Si recordamos que la familia suele considerarse trasunto de la nación, este modelo familiar refuerza un esquema patriarcal de la sociedad como conjunto.

\section{OBRAS CITADAS}

Assmann, Aleida (1999): Erinnerungsräume. Formen und Wandlungen des kulturelle Gedächtnis. Munich, C. H. Beck.

— ; y Sebastian, Conrad (eds.) (2010): Memory in a Global Age: Discourses, Practices, Trajectories. Houndmill, Basingstoke, Palgrave Macmillan.

Burdiel, Isabel (2015) "Lo que las novelas pueden decir a los historiadores. Notas para Manuel Pérez Ledesma". En José Álvarez Junco, Rafael Cruz Martínez y Florencia Peyrou, (eds.): El historiador consciente. Homenaje a Manuel Pérez Ledesma. Madrid, Marcial Pons.

Calderón Puerta, Aránzazu; y Chmielewska, Katarzyna (2019): "Memoria, política histórica y habitus histórico-identitario". En A. Calderón Puerta, D. Jarzombowska, H. González Fernández y K. Moszczyńska-Dürst (eds.): Memoria encarnada, género y silencios en España y América Latina. Siglo XXI. Sevilla, Padilla Libros Editores y Libreros.

Calderón Puerta, Aránzazu; Moszczyńska-Dürst, Katarzyna (2016): //www.facebook.com/ groups/1747851205442413/permalink/1887291051498427/. Entrevista a Almudena Grandes durante el Simposio "¿Corazón helado? Narradoras españolas contemporáneas desde la teoría de las emociones". Instituto de Estudios Ibéricos e Iberoamericanos de la Universidad de Varsovia" (Varsovia, 12 de mayo de 2016). Recogido en: Facebook del Grupo de investigación GENIA: Género, identidad y discurso en España y América Latina del Instituto de Estudios Ibéricos e Iberoamericanos de la Universidad de Varsovia [última visita: 20.3.2018].

\footnotetext{
determinada visión de la experiencia histórica del grupo o los grupos con que un ciudadano se identifica por razón de esas ideas" (2006: 37).

${ }^{25}$ En el marco de una heteronormatividad compulsiva, recurriendo a una expresión de Meri Torras.
} 
Faber, Sebastiaan (2014): "Actos afiliativos y postmemoria: asuntos pendientes", Pasavento. Revista de Estudios Hispánicos, vol. II, n 1, pp. 137-155.

Foucault, Michel (1980): Power/Knowledge. Nueva York, Panteón.

Grandes, Almudena (2011) [2010]: Inés y la alegría. El ejército de la Unión Nacional Española y la invasión del valle de Arán, Pirineo de Lérida, 19-27 de octubre de 1944. Barcelona, Maxi Tusquets Editores.

- (2012): El lector de Julio Verne. La guerrilla de Cencerro y el trienio del terror. Jaén, Sierra Sur, 1947-1949. Barcelona, Maxi Tusquets Editores.

— (2017): Los pacientes del doctor García. El fin de la esperanza y la red de evasión de jerarcas nazis dirigida por Clara Stauffer, Madrid-Buenos Aires, 1945-1954. Barcelona, Maxi Tusquets Editores.

Jenkins, Keith (2009): Repensar la Historia. Madrid, Siglo XXI.

Lowenthal, David (1998): El pasado es un lugar extraño. Madrid, Akal.

Moszczynska-Durst, Katarzyna (2017): De las intimidades congeladas a los marcos de guerra: amor, identidad y transición en las novelistas españolas. Sevilla, Padilla Libros Editores y Libreros.

Ricœur, Pièrre (2010): La memoria, la historia, el olvido. Madrid, Trotta.

Rosa, Isaac (2004): El vano ayer. Barcelona, Seix Barral.

Sabadell-Nieto, Joana (2011): Desbordamientos. Transformaciones culturales y políticas de las mujeres. Barcelona, Icaria.

Tébar Hurtado, Javier (ed.) (2012): "Resistencia ordinaria". La militancia y el "antifranquismo" catalán ante el Tribunal de Orden Público (1936-1977). Valencia, Universitat de València.

Traverso, Enzo (2012): La historia como campo de batalla: interpretar las violencias del siglo $x x$. Buenos Aires, Editorial Fondo de Cultura Económica. 